\title{
Subsidence by liquefaction-fluidization in man-made strata around Tokyo bay, Japan: from geological survey on damaged part at the 2011 off the Pacific Coast of Tohoku Earthquake
}

\author{
O. Kazaoka ${ }^{1}$, S. Kameyama ${ }^{2}$, K. Shigeno ${ }^{3}$, Y. Suzuki ${ }^{3}$, M. Morisaki ${ }^{1}$, A. Kagawa ${ }^{1}$, T. Yoshida ${ }^{1}$, \\ M. Kimura ${ }^{1}$, Y. Sakai ${ }^{1}$, T. Ogura ${ }^{1}$, T. Kusuda ${ }^{\text {a }}$, and K. Furuno ${ }^{\text {a }}$ \\ ${ }^{1}$ Research Institute of Environmental Geology, Chiba (RIEGC), Japan \\ ${ }^{2}$ Environmental Protection division of Chiba Prefectural Government, Japan \\ ${ }^{3}$ Meiji Consultante Co., Ltd, Japan \\ ${ }^{\mathrm{a}}$ Former member of Research Institute of Environmental Geology, Chiba
}

Correspondence to: O. Kazaoka (osamu.kazaoka@gmail.com)

Published: 12 November 2015

\begin{abstract}
Geological disaster by liquefaction-fluidization happened on southern part of the Quaternary PaleoKanto submarine basin at the 2011 Earthquake off the Pacific Coast of Tohoku. Liquefaction-fluidization phenomena occurred mainly in man-made strata over shaking 5+ intensity of Japan Meteorological Agency scale. Many subsided spots, $10-50 \mathrm{~m}$ width, 20-100 $\mathrm{m}$ length and less than $1 \mathrm{~m}$ depth, by liquefaction-fluidization distributed on reclaimed land around northern Tokyo bay. Large amount of sand and groundwater spouted out in the terrible subsided parts. But there are little subsidence and no jetted sand outside the terrible subsided part. Liquefaction-fluidization damaged part at the 1987 earthquake east off Chiba prefecture re-liquefied and fluidized in these parts at the 2011 great earthquake. The damaged area were more wide on the 2011 earthquake than the 1987 quake. Detailed classification maps of subsidence by liquefaction-fluidization on the 2011 grate earthquake were made by fieldwork in Chiba city around Tokyo bay. A mechanism of subsidence by liquefactionfluidization in man-made strata was solved by geological survey with continuous large box cores on the ACE Liner and large relief peals of the cores at a typical subsided part.
\end{abstract}

\section{Introduction}

Strong shaking hit the Kanto district and the Tohoku district at the 2011 off the Pacific Coast of Tohoku Earthquake. Strong shaking over 5+ intensity of Japan Meteorological Agency scale distributed widely in southeast part of the Neogene Kanto Basin (JMA, 2011; Fig. 1). The shaking 5+ intensity of JMA scale correlate with about 8 intensity of MSK scale. Liquefaction-fluidization phenomena caused on reclaimed land by hydraulic fill in the strong shaking area at the Neogene Kanto Basin (RIEGC, 2011c; Fig. 1).

\section{Distribution of liquefaction-fluidization site on} Boso Peninsula

Liquefaction-fluidization sites were distributed on north part of the Boso peninsula, southeastern Neogene Kanto Basin at the earthquake (RIEGC, 2011c; Fig. 2). Many of these liquefaction- fluidization sites had been caused liquefactionfluidization phenomena at the 1987 east off Chiba prefecture earthquake (RIEGC, 2011a; RIEGC,2011c; Fig. 3). Each liquefaction-fluidization sites at the 2011 earthquake is more wide than the liquefaction-fluidization sites at the 1987 earthquake.

Liquefaction-fluidization sites concentrate on belts with $0.5 \mathrm{~km}$ wide, NE-SW extending on reclaimed land along 


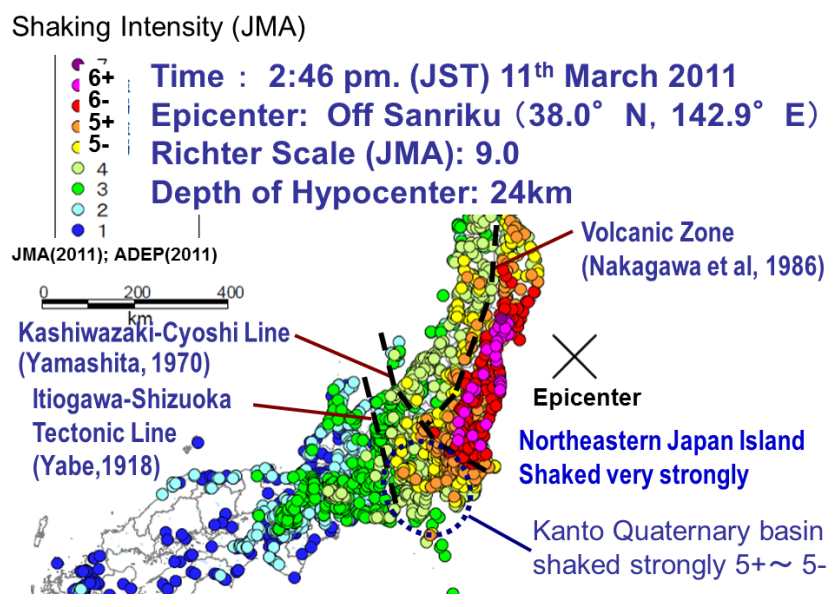

Figure 1. Distribution of JMA intensity on the 2011 Earthquake off the Pacific Coast of Tohoku and geological structure.

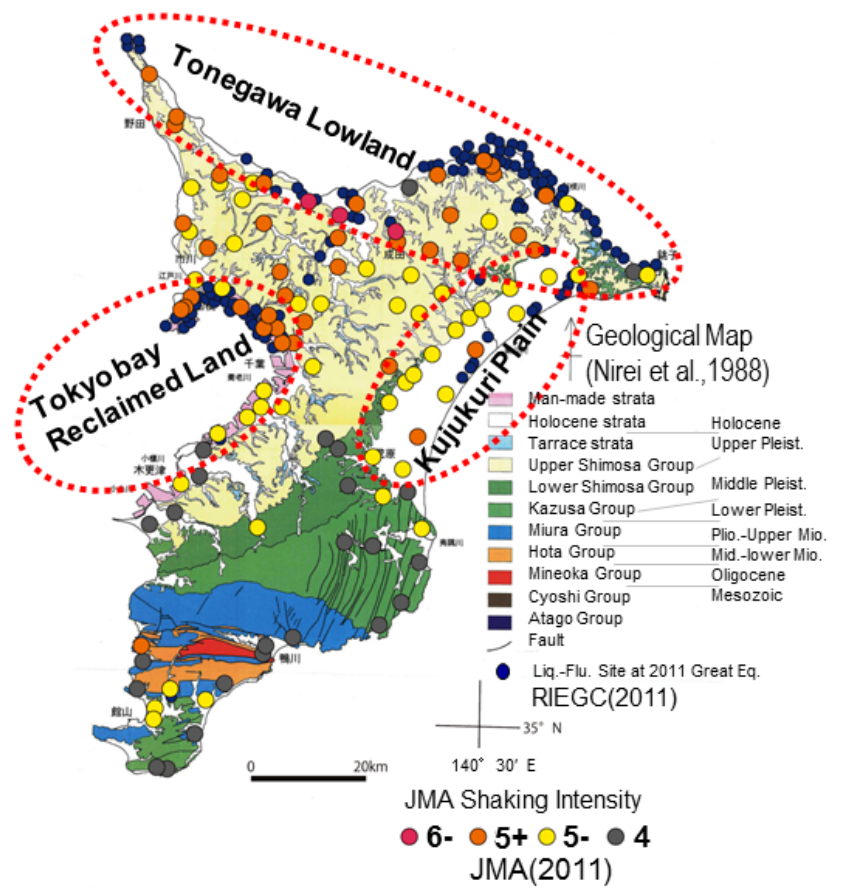

Figure 2. Distribution of liquefaction-fluidization phenomena and JMA intensity by the 2011 Earthquake.

Tokyo bay (RIEGC, 2011a, c; Fig. 4). These belts may be on the thick part of the Alluvium formation after the Wurm glacial stage (Kazaoka, 2011; RIEGC, 2011b; Fig. 5).

Liquefaction-fluidization phenomena caused partially with subsidence on the reclaimed land of northern Tokyo bay at the 2011 earthquake. Many subsided spots, 10$50 \mathrm{~m}$ width, 20-100 $\mathrm{m}$ length and less than $1 \mathrm{~m}$ depth, by liquefaction-fluidization distributed on reclaimed land around northern Tokyo bay. Large amount of sand and groundwater spouted out in the terrible subsided parts. But

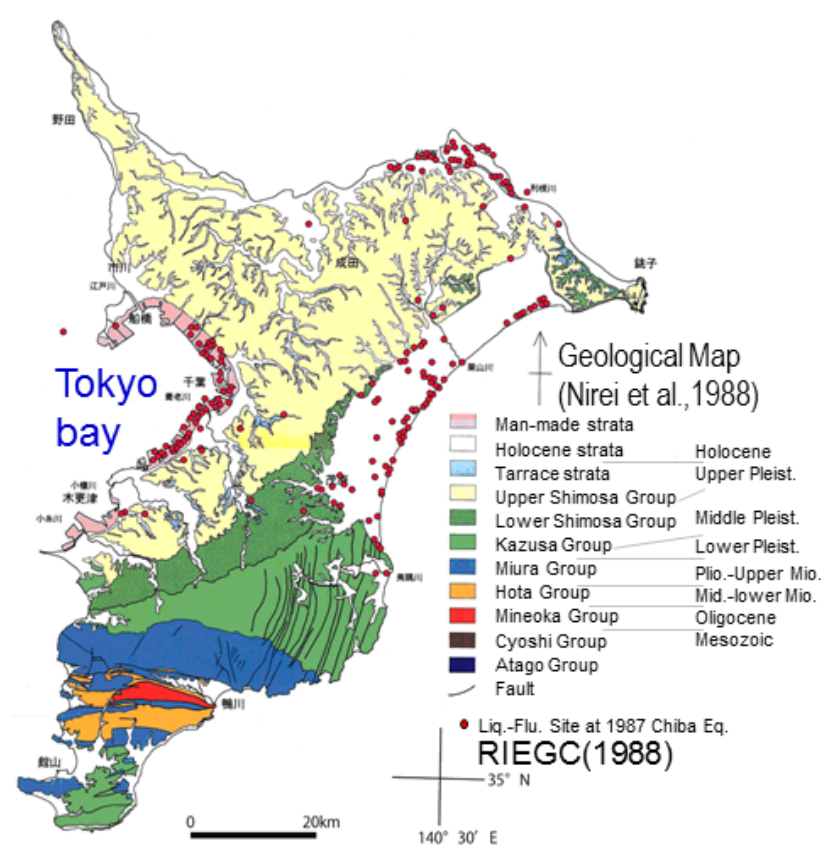

Figure 3. Distribution of liquefaction-fluidization phenomena by the 1987 east off Chiba prefecture earthquake.

there are little subsidence and no jetted sand outside the terrible subsided part. Detailed classification maps of subsidence by liquefaction-fluidization on the grate earthquake were made by fieldwork in Chiba city around Tokyo bay (RIEGC, 2011c; Fig. 6).

\section{Mechanism of subcidence by liquefaction-fluidization in manmade-strata}

A mechanism of subsidence by liquefaction-fluidization in man-made strata was solved by geological survey with continuous large box cores on the ACE Liner (Fig. 7) and continuous boring cores in Chiba city (Fig. 6). Continuous box core samples from surface to 5-7 m depth could be taken at the each 3-5 $\mathrm{m}$ length from little subsided part to terrible subsided part (Fig. 8). Detailed litho-stratigraphy, sedimentary structure, dencity and hardness of strata were studied on the continuous box core samples, continuous boring core samples and large relief peels of the cores (RIEGC, 2014). These data indicate that:

1. The thickness of man-made strata is about $12 \mathrm{~m}$.

2. Man-made strata is composed of Dumped Association, Upper Filling Association and Lower Filling Association (RIEGC, 2014; Figs. 9, 10). Two Filling Associations were made by sand pump method from bottom sediments in the Tokyo bay. Upper Filling Association consists of lowermost, lower, upper and uppermost bundle.

3. Litho-facies of each man-made strata is as follows.

Dumped Association: This association is composed of $1.5-2.2 \mathrm{~m}$ thick sandy silt to silty fine sand layers with silt- 


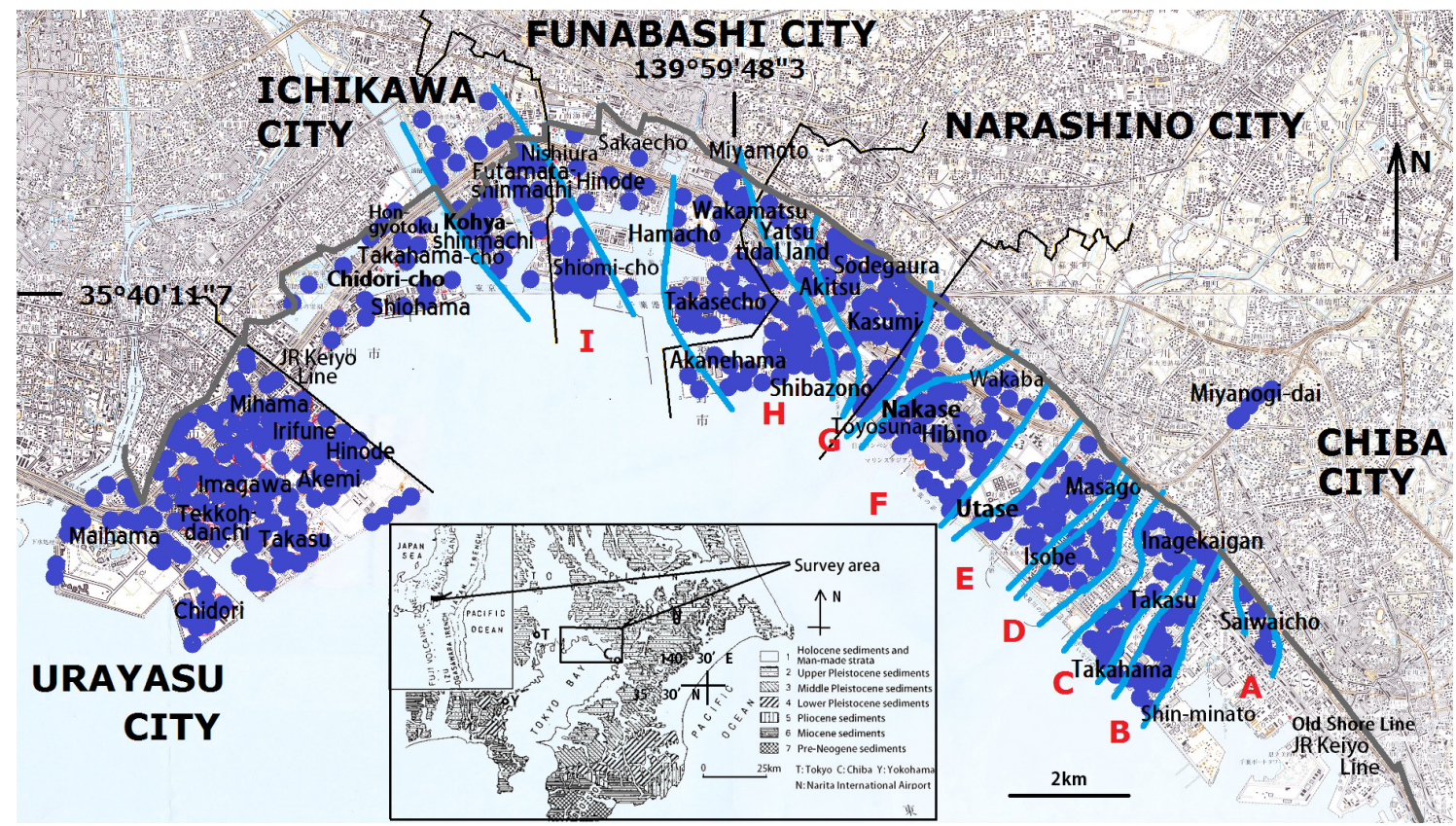

Figure 4. Distribution of liquefaction-fluidization phenomena. Blue spot means liquefaction-fluidization site (Kazaoka et al., 2011).

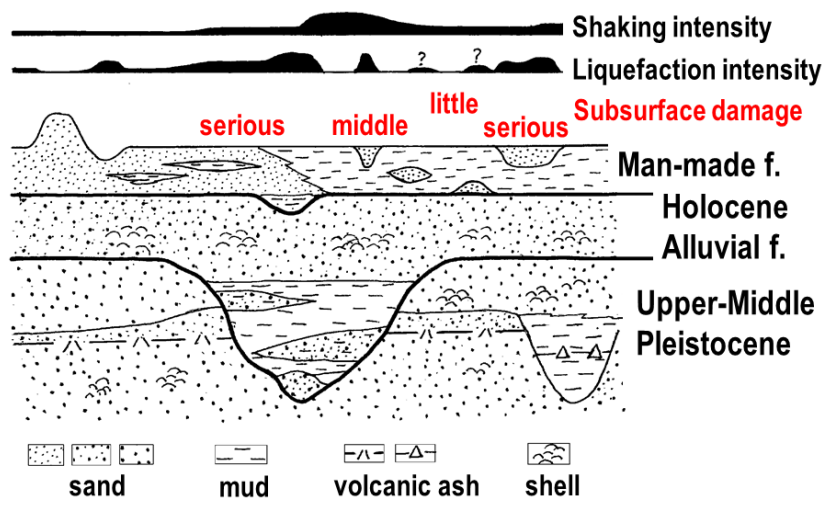

Figure 5. Idealized geological cross section on reclaimed land of Tokyo bay. Intensity of shaking and liquefaction show line wideth (Kazaoka, 2011).

stone brocks and rock gravels. Sand dike of yellowish brown sand and gray sand distribute rarely (RIEGC, 2014; Fig. 11).

Uppermost Bundle of Upper Filling Association: this bundle is composed of $0.2-0.8 \mathrm{~m}$ thick yellowish brown laminated fine to medium sand layers. Upper part of this bundle lost partially primary sedimentary structures and loose. The feature described above suggests that the losting structure part is liquefaction-fluidization part. The base of this bundle consists of laminated coarse-very coarse sandy shell fragment layers.

Upper Bundle of Upper Filling Association: this bundle is composed of 0.4-1.8 $\mathrm{m}$ thick gray laminated medium sand layers. Shell fragment layers often interbeded in this sand

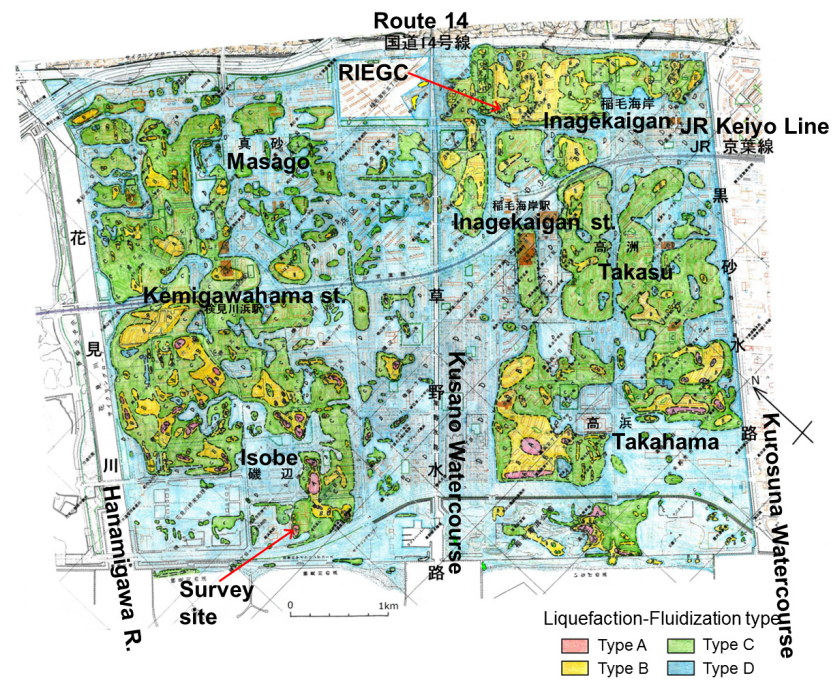

Figure 6. Classification of subsidence by liquefaction-fluidization on the 2011 earthquake in the reclaimed land in Chiba city. A Type: subsidence $>0.3 \mathrm{~m}$, B type: $0.3 \mathrm{~m}<$ subsidence $<0.1 \mathrm{~m}$, C Type: $0.1 \mathrm{~m}<$ subsidence < few centimeter, D Type: no subsidence.

layers. The sand layers lost widely primary sedimentary structures and very loose or relatively dence.

Lower Bundle of Upper Filling Association: this bundle is composed of 0-1.8 $\mathrm{m}$ thick gray silt layers.

Lowermost Bundle of Upper Filling Association: this bundle is composed of $0.7-1.8 \mathrm{~m}$ thick gray shelly medium sand layers. Shell fragment layers often interbedded in the shelly sand layers. In upper part of this bundle, sand layer lost 

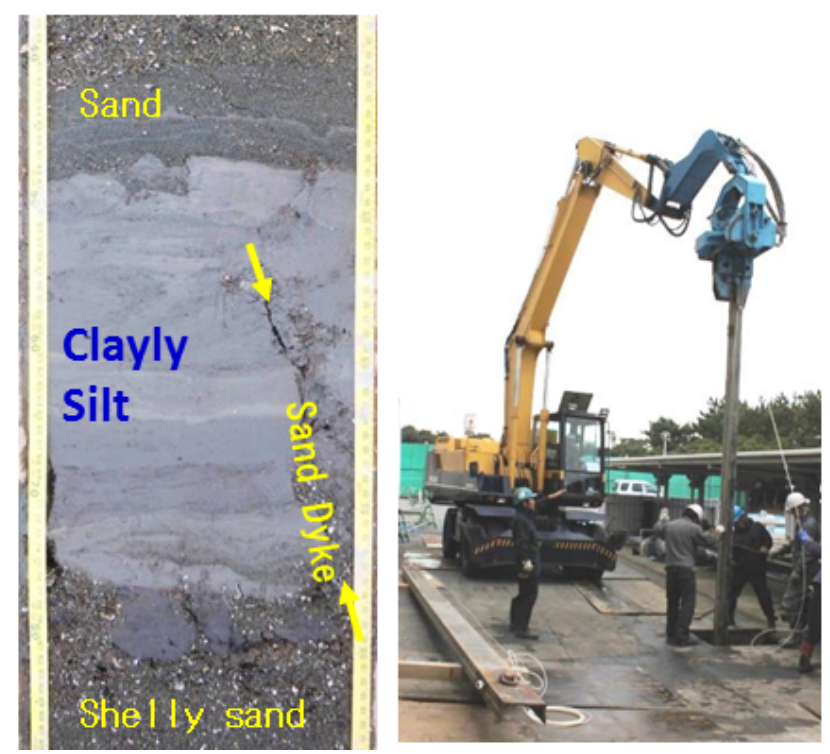

Figure 7. Continuous sampling by ACE liner and continuous man-made strata samples on this survey site.
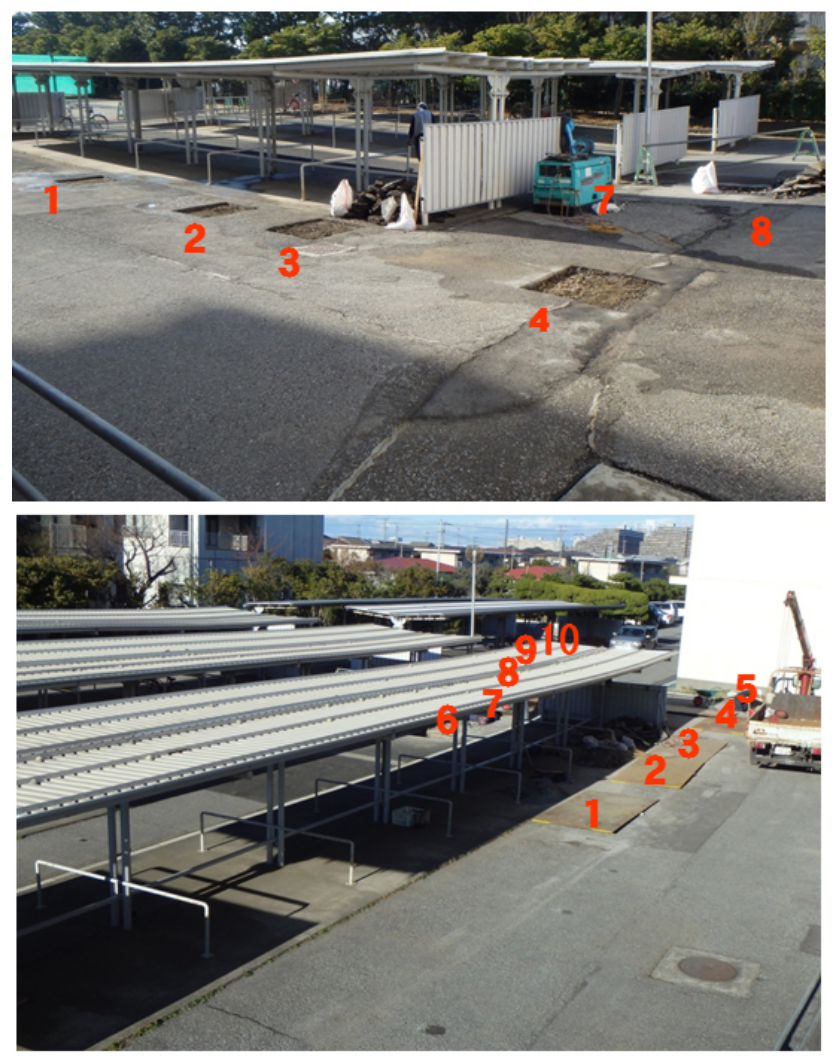

Figure 8. Distribution of subsidence and sampling points by ACE liner. Ground surface subside a little at the sampling points No. 4, 5, 9 and 10. The surface subsided $0.4 \mathrm{~m}$ height at the sampling points No. 1, 2, 6 and 7 . Roofs were deformed by subsidence. 


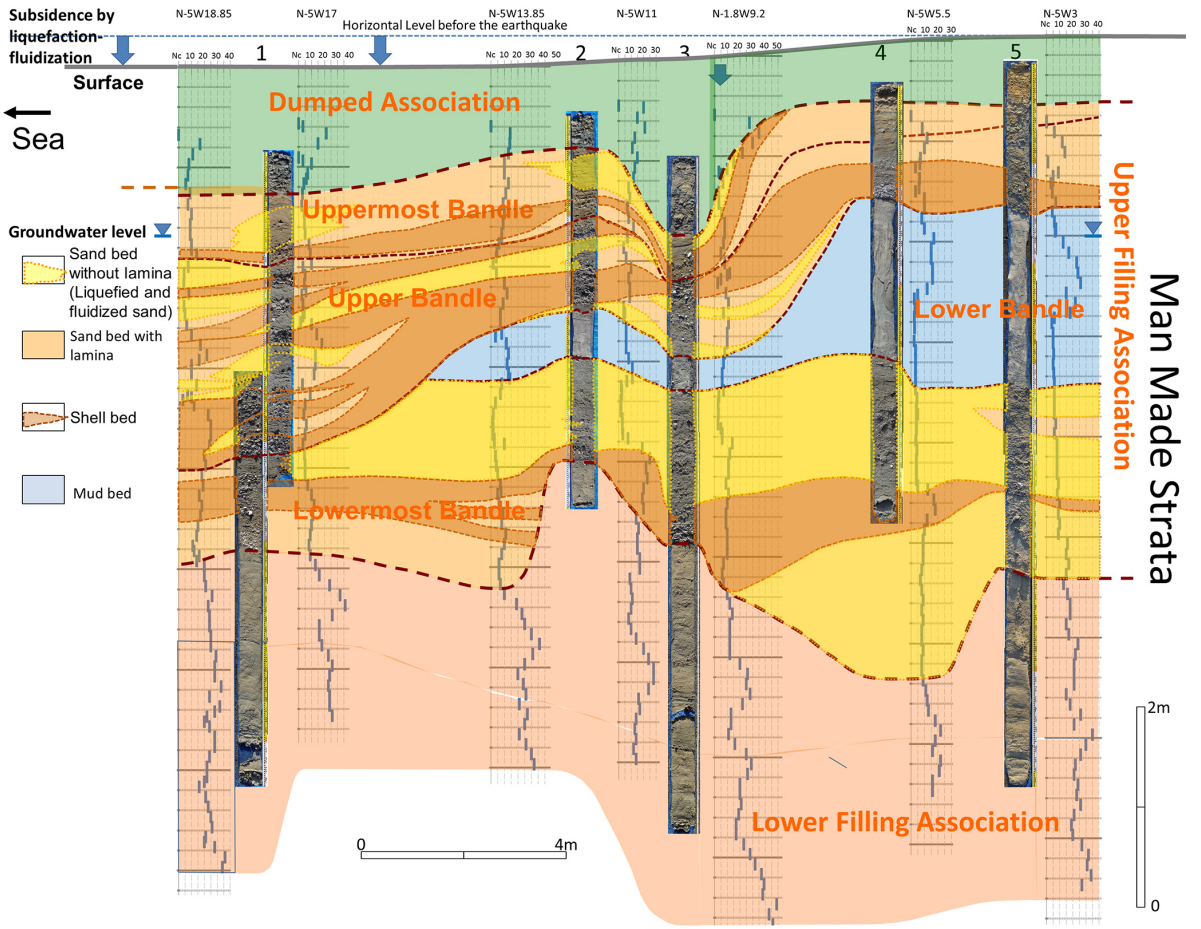

Figure 9. Geological cross section from No. 1 to No. 5 sampling points of Fig. 8.

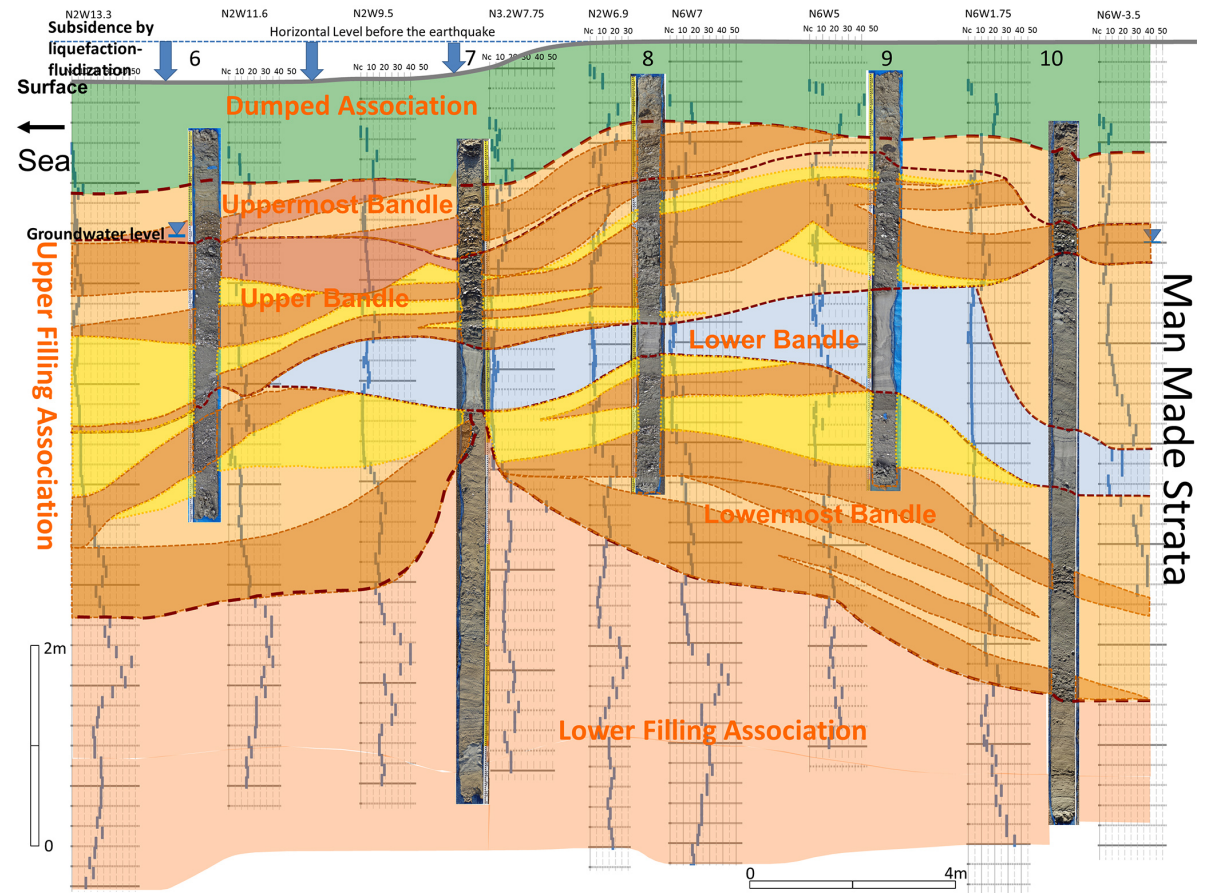

Figure 10. Geological cross section from No. 6 to No. 10 sampling points of Fig. 8. 


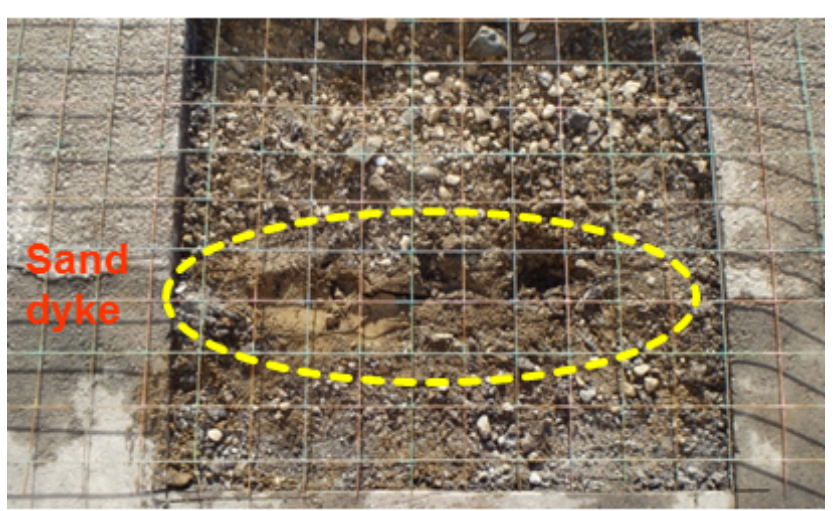

Figure 11. Jetted yellowish gray sand along fisher on No. 4 point of Fig. 2.

widely primary sedimentary structures. The medium sand injected in the upper silt layers.

Lower Filling Association: this association is composed of 0.5-3.5 m thick yellowish gray laminated relatively dence matrix free good sorted fine-medium sand layers. The sand layers lost partially primary sedimentary structure. The liquefaction-fluidization part is cut by the Upper Filling Association.

4. Liquefaction-fluidization parts are in lowermost bundle, upper bundle and uppermost bundle of the Upper Filling Association.

5. Subsidence part is entirely identical with distribution of liquefaction-fluidization part in upper bundle of the Upper Filling Association.

Acknowledgements. We thank Yuji Takanashi and Yutaka Yazawa, former Chief of Chiba Environmental Research Center and Hiroaki Hiura, Chief of Chiba Environmental Research Center for helpful to study and survey liquefaction-fluidization.

\section{References}

Japan Meteorological Agency: The seismological bulletin of the Japan Meteorological Agency for March 2011, Japan Meteorological Agency, 321 pp., 2011.

Kazaoka, O.: Liquefaction-fluidization damage and geological structure of Man-made strata, Symposium for Disaster in man-made strata and 2011 Tohoku Earthquake, Japanese Society of Geo-pollution Science, Medical Geology and Urban Geology, 1-21, 2011. Kazoka, O., Furuno, K., Kagawa, A., Kusuda, T., Sakai, Y., Yoshida, T., Kato, A., Yamamoto, M., and Takanashi, Y.: Distribution of Geological Disaster by Liquefaction-Fluidization Phenomena at The 2011 off the Pacific coast of Tohoku Earthquake on Tokyo Bay Reclaimed Land, Jour. Geo-Pol. Sci., Med. Geol. and Urban Geol., 7, 10-21, 2011.

Kazaok, O., Kameyama, S., Morisaki, M., Shigeno, K., Suzuki Y., Kagawa A., Yoshida T., Kimura, M., Sakai, Y., and Ogura, T.: Characteristic of Man-made strata in liquefaction-fluidization site at the 2011 off the Pacific coast of Tohoku Earthquake: from geologaical survey on reclaimed land in Isobe district around Tokyo bay, Chiba city, Proceedings of the 24th Symposium on Geo-Environments and Geo-Technics, Japanese Society of Geopollution Science, Medical Geology and Urban Geology, 9-14, 2014.

Nirei, H., Kusuda, T., Suzuki, K., Kamura, K., Furuno, K., Hara, Y., Satoh, K., and Kazaoka, O.: The 1987 East off Chiba Prefecture Earthquake and its Hazard, Memoir of Geological Society of Japan, Geological Society of Japan, no. 35, 31-46, 1990.

RIEGC: Liquefaction-Fluidization Phenomena on Boso Peninsula at the 2011 Earthquake off the Pacific Coast of Tohoku, Central Japan: Part 1. RESEARCH REPORT G-8, Chiba Environmental Research Center, 1-1-1-8, 2011a.

RIEGC: Liquefaction-Fluidization Phenomena on Boso Peninsula at the 2011 Earthquake off the Pacific Coast of Tohoku, Central Japan: Part III, RESEARCH REPORT G-8, Chiba Environmental Research Center, 3-1-3-26, 2011 b.

RIEGC: Liquefaction-Fluidization Phenomena on Boso Peninsula at the 2011 Earthquake off the Pacific Coast of Tohoku, Central Japan: Part IV. RESEARCH REPORT G-8, Chiba Environmental Research Center, 4-1-4-69, 2011c.

RIEGC: Liquefaction-Fluidization Phenomena on Boso Peninsula at the 2011 Earthquake off the Pacific Coast of Tohoku, Central Japan: Part V. RESEARCH REPORT G-8, Chiba Environmental Research Center, 5-1-5-8, 2012.

RIEGC: Liquefaction-Fluidization Phenomena on Boso Peninsula at the 2011 Earthquake off the Pacific Coast of Tohoku, Central Japan: Part VI., Chiba Environmental Research Center, 4P (http://www.pref.chiba.lg.jp/wit/chishitsu/ekijoukahoukoku/ documents/6-2.pdf), 2014. 